\title{
RANCANG BANGUN SISTEM MANAJEMEN USER AAA (AUTHENTICATION, AUTHORIZATION, ACCOUNTING) DAN MONITORING JARINGAN HOTSPOT BERBASIS WEB
}

\author{
Achmad Fauzi ${ }^{1}$, Joseph Dedy Irawan $^{2}$, Nurlaily Vendyansyah ${ }^{3}$ \\ Program Studi Teknik Informatika S1, Fakultas Teknologi Industri \\ Institut Teknologi Nasional Malang, Jalan Raya Karanglo km 2 Malang, Indonesia \\ achmaff@gmail.com
}

\begin{abstract}
ABSTRAK
Pada saat ini pengolahan terhadap koneksi jaringan komputer sudah sangat diperlukan . Dengan pengelohan suatu sistem pada jaringan komputer akan memberikan kemudahan bagi administrator untuk lebih efisien dalam mengolah jaringan. Pada saat ini pengolahan terhadap user pada laboratorium teknik informatika itn malang yang terkoneksi jaringan wireless yang ter-integrasi dengan server radius eksternal belum diterapkan, terutama untuk pengolahan penambahan user, pengolahan kecepatan bandwidth user, limitasi waktu user terkoneksi, dan kemudian aktifitas memantau user .

Sistem Manajemen User dan Monitoring Jaringan Hotspot Pada Server Radius terdapat 3 bagian . Bagian pertama Authentication dimana user sebelum memasuki jaringan yang akan di akses akan memasukkan username dan password. Bagian kedua Authorize proses ini setelah terjadinya authentication, ketika user memasukkan username dan password yang sesuai, maka user dapat mengakses jaringan tersebut proses ini yang dinamakan authorize. Bagian Ketiga Accounting proses ini dimana administrator dapat mengolah user, dalam hal mengolah bandwidth maupun limit waktu user .

Dari Hasil dari pengujian sistem menunjukkan bahwa fungsi dari manajemen user layanan hotspot, monitoring user layanan hotspot, dan monitoring router mikrotik dapat berjalan sesuai dengan fungsinya, sistem dapat membuat user baru, alokasi bandwidth setiap user, monitoring aktifitas user. Sehingga dapat membantu administrator jaringan dalam mengolah jaringan komputer, terutama dalam pengolahan data user dalam layanan hotspot .
\end{abstract}

Kata kunci : Server Radius, Wireless, Hotspot, AAA, Bandwidth, Web

\section{PENDAHULUAN}

\subsection{Latar Belakang}

Pada saat ini pengolahan terhadap koneksi jaringan komputer sudah sangat diperlukan . Dengan pengelohan suatu sistem pada jaringan komputer akan memberikan kemudahan bagi administrator untuk lebih efektif dan efisien dalam mengolah jaringan , terutama pada bagian pengolahan terhadap user yang terkoneksi dengan jaringan komputer dengan menggunakan wireless . Pada saat ini pengolahan terhadap user pada laboratorium teknik informatika itn malang yang terkoneksi jaringan wireless yang ter-integrasi dengan server radius eksternal belum diterapkan, terutama untuk pengolahan penambahan user, pengolahan kecepatan bandwidth user, limitasi waktu user terkoneksi, dan kemudian aktifitas memantau user. Dengan sistem pengolahan yang dibuat oleh penulis dapat berjalan dengan baik dan membantu administrator lebih efektif dan efisien dalam mengolah jaringan .

Server Radius Eksternal merupakan server yang dapat menampung user pada database server tersebut , dimana nantinya user yang di tampung pada server dapat melakukan Authentication, Authorization, dan Accounting dalam mengakses jaringan komputer . Dengan server ini administrator dapat mengolah data user yang tersimpan pada server, dengan server radius ini di harapkan dapat mengolah data user lebih efektif dan efisien .
Sistem Server Radius Eksternal dapat bekerja dengan beberapa bantuan perangkat jaringan , salah satunya yang terpenting adalah NAS (Network Access Server ) merupakan sebuah perangkat jaringan yang berfungsi untuk menyimpan data user yang kemudian user yang tersimpan akan ter-integrasi dengan Server Radius Eksternal, setelah sistem sudah terkoneksi maka user akan mencoba terkoneksi dengan jaringan, apabila user yang telah disimpan tersebut ada maka user akan melakukan otentikasi dan kemudian user dapat terkoneksi dengan jaringan, apabila user belum tersimpan pada Server Radius maka proses otentikasi user akan di tolak ,maka user tidak dapat terkoneksi dengan jaringan tersebut .

Manajemen bandwidth dapat di sebut juga pengalokasian yang terstruktur dari suatu bandwidth untuk mendukung kebutuhan dan suatu layanan jaringan internet . bandwidth diartikan sebagai kapasitas suatu komunikasi ketik suatu data melewati suatu koneksi jaringan. Bandwidth memiliki satuan yaitu bit, kbit dan bps . Pengalokasian bandwidth dapat juga disebut dengan QOS ( Quality Of Service )[5]

Oleh karena itu peneliti membuat sistem yang diharapkan dapat memudahkan administrator jaringan dalam mengolah user yang terkoneksi dengan jaringan wireless terutama jaringan yang ter integrasi dengan Router Mikrotik pada layanan Hotspot . Pada Sistem ini di lengkapi dengan fitur CRUD ( Create, 
Reset, Update, Delete ) sebagai bentuk kemudahan dalam mengolah data user. Dengan pengolahan data user, administrator dapat Create User pada Server, Create Kecepatan Bandwidth user dan Monitoring aktifitas user dengan basis website. Kemudian Administrator juga dapat monitoring Aktifitas dari Router Mikrotik .

\subsection{Rumusan Masalah}

Berdasarkan Permasalahan yang dipaparkan di Latar Belakang dapat di kembangkan sebagai berikut

1. Bagaimana cara membangun Sistem Manajemen User dan Monitoring ?

2. Bagaiamana cara membangun Sistem Manajemen User dan Monitoring pada Laboratorium Teknik Informatika S-1 Malang ?

3. Bagaimana cara mengembangkan Sistem Manajemen dan Monitoring Berbasis Web ?

\subsection{Batasan Masalah}

Agar penulisan dalam membangun sistem tidak meluas, maka penelitian ini memiliki batas permasalahan sebagai berikut :

1. Monitoring ini hanya dapat di koneksikan dengan satu jaringan hotspot.

2. Bahasa pemrograman yang di gunakan pada sistem ini yaitu PHP

3. Variable data yang digunakan berupa :
a. IP Address
b. Username
c. Mac Address
d. Waktu Akses User

4. Monitoring user di tampilkan dalam bentuk logger

5. Sistem ini hanya dapat digunakan dalam platform web .

6. Studi Kasus yang digunakan untuk penelitian adalah mahasiswa teknik informatika pada kampus Institut Teknologi Nasional Malang.

\subsection{Tujuan}

Adapun tujuan yang ingin dicapai dari perancangan manajemenan dan monitoring user adalah :

1. Membangun Server Radius Menggunakan Linux Ubuntu dan konfigurasi Freeradius pada Server untuk manajemen User dan Monitoring User pada layanan hotspot.

2. Menggunakan IP Address, Username, Mac Address, Waktu Akses User sebagai data user yang digunakan untuk membangun sistem manajemen user dan monitoring.

3. Menghasilkan Sistem Manajemen dan Monitoring User berbasis WEB menggunakan bahasa pemrograman PHP dan MYSQL sebagai database.

\section{TINJAUAN PUSTAKA}

Remote Access dial up user service (RADIUS), dibuat oleh Livingston Enterprises, merupakan sebuah server yang memverifikasi dan mengotentikasi user umumnya berdasarkan pada metode challenge dan response. RADIUS memiliki sistem authentication terpusat, pengatur authorization , dan accounting user baik yang diperlukan atau diinginkan.[1]

Radius adalah sebuah server yang menyediakan mekanisme sistem login user dengan sebuah keamanan yaitu dengan sistem authentication dan authorization yang di lakukan user . proses otentikasi di lakukan dengan memasukkan username dan password yang telah di daftarkan pada sistem server . jika proses otentikasi dan otoriasi berhasil maka proses akunting di lakukan, sistem dapat mencatat semua aktifitas user, seperti tanggal dan jam akses sebuah user.[2]

Memonitor jaringan, yaitu untuk memantau perubahan pada jaringan komputer dan juga untuk mendeteksi perubahan yang tidak terduga dan mendadak dalam jaringan komputer. Perubahan tidak terduga seperti yang mungkin terjadi seperti router gagal terkoneksi . [3]

\subsection{Server Radius}

RADIUS adalah singkatan dari Remote Authentication Dial-in User Service yang berfungsi untuk meberikan layanan keamanan seperti authentication ID dan password dan manajemen bandwidth dan batas masa aktif user pada jaringan komputer . Radius Server diterapkan pada jaringan komputer dengan model client-server.

Radius merupakan protokol yang dikembangkan untuk proses AAA (authentication, authorization, and accounting) [4]

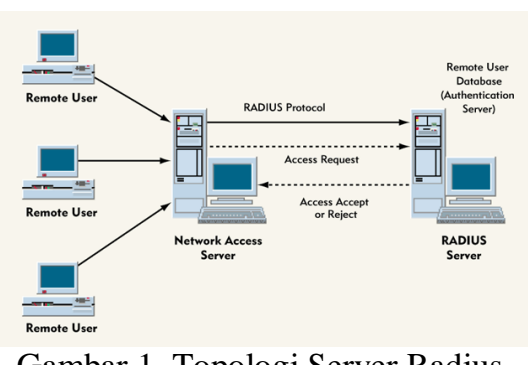

Gambar 1. Topologi Server Radius

\subsection{AAA}

\section{A. Authentication}

Authentication Merupakan suatu proses untuk memverifikasi identitas yang digunakan oleh user untuk masuk pada jaringan komputer. Menggunakan kombinasi dari ID dan password untuk memasuki suatu jaringan komputer .Seperti yang kita ketahui bahwa password tersebut dapat diketahui oleh orang lain, maka hal tersebut akan menggunakan proses authentication sehingga orang lain tidak dapat masuk dalam sistem . Dalam situs ecommerce dan situs-situs internet bisnis lainnya, membutuhkan authenticaticator yang lebih kuat dan lebih dapat 
dipercaya.. Proses authentication diperlukan ketika administrator mempunyai kebutuhan untuk membatasi siapa saja yang diperbolehkan masuk ke dalam sistem jaringan komputer yang dimanajemen oleh administrator. Untuk memenuhi kebutuhan tersebut, user yang ingin mengakses sebuah jaringan komputer secara harus terdaftar terlebih dahulu pada sistem manajemen jaringan. User yang ingin masuk kedalam jaringan komputer tersebut perlu diketahui dahulu sebelum bebas mengkases jaringan tersebut. Pengenalan ini bertujuan untuk mengetahui apakah user tersebut berhak mengakses jaringan atau tidak .

\section{B. Authorization (Otorisasi)}

Authorization merupakan proses yang memutuskan apakah user dapat mengakses jaringan tersebut atau tidak . Sebagai contoh, dalam perusahanan yang bergerak pada penyedia layanan internet atau ISP, ISP berhak memutuskan apakah akan memberikan alamat IP Static atau alamat IP DHCP. Administrator yang harus memanajemen Proses authorization ini setelah proses authentication berhasil . Ketika user yang ingin megakses jaringan komputer anda telah terdaftar maka user dapat terkoneksi jaringan komputer tersebut, sehingga administrator berhak dalam manajemen proses hak akses user ketika akan terkoneksi dengan jaringan komputer .

\section{Accounting (Akunting)}

Accounting Merupakan bagian akhir dari kerangka kerja AAA, accounting dapat mengukur dan mencatat sumber daya yang telah digunakan, termasuk jumlah waktu atau jumlah data yang dikirim dan atau diterima selama pelanggan tersebut memanfaatkan sumber daya tersebut . Sistem Accounting dapat di lakukan setelah proses authentication dan authorization, dimana administrator dalam sistem akunting ini dapat memanajemen suatu user yang telah di daftarkan sebelumnya, seperti manajemen setiap bandwidth user yang terdaftar dan manajemen batas masa aktif user atau yang biasa disebut dengan sistem billing, sehingga penggunaan sumberdaya jaringan komputer lebih efektif .

\subsection{Hotspot}

Hotspot adalah zona area yang menyediakan akses internet menggunakan jaringan nirkabel. Dalam penggunaan umum, terdapat perbedaan dengan wifi, wifi merupakan teknologi yang digunakan komunikasi menggunakan jaringan nirkabel, yang memungkinkan berbagai perangkat dapat mengakses jaringan tersebut [6].

\section{4. $\mathrm{MySQL}$}

Database merupakan salah satu aspek yang penting dalam penyimpanan suatu data, sistem informasi yang besar harus didukung oleh database yang handal, salah satunya MySQL Server merupakan salah satu software yang didistribusikan secara gratis di bawah lisensi GPL (General Public Licence).[7]

\section{METODE PENELITIAN}

3.1. Topologi Jaringan

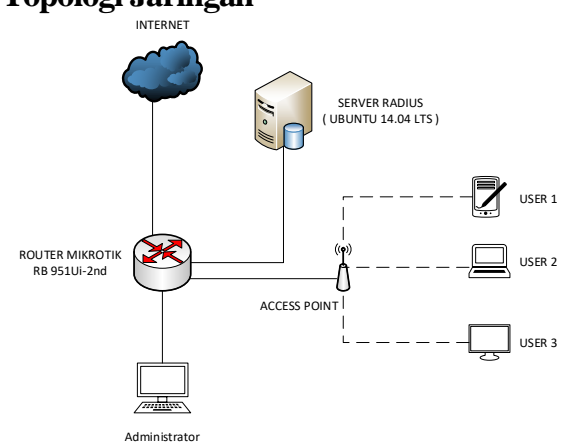

Gambar 2. Topologi Jaringan

Pada Gambar 2 merupakan topologi jaringan yang akan di gunakan dimana Internet sebagai uji coba untuk limitasi bandwidth setelah system sudah jadi. Kemudian di hubungkan dengan router mikrotik yang di gunakan untuk konfigurasi hotspot dan administrator sebagai controller . PC Server Radius di hubungkan dengan router mikrotik kemudian di hubungkan menggunakan access point sebagai pemancar sinyal, kemudian terdapat 3 user yang di hubungkan ke hotspot yang telah di konfigurasi . Berikut Penjelasan Ethernet pada Router mikrotik.
1. Ethernet $1 \quad$ : Internet
2. Ethernet $2:$ PC Server Radius ( IP Address : 192.168.99.1)
3. Ethernet $3 \quad$ : Access Point ( IP Address : 10.10.5.1)
4. Ethernet 4 : Administrator (IP Address : 192.168.87.1 )

\subsection{Flowchart Sistem}

Pada Gambar 3. merupakan Flowchart dari alur jalan nya sistem, yang berawal dari login admin untuk membuka sistem web based. Admin login menggunakan username dan password, sistem akan melakukan pengecekan dengan database, kemudian admin dapat mengolah data user mengatur kecepatan bandwidth dan limitasi waktu dari web based yang di buat, dimana data user tersimpan pada server radius yang sudah terkoneksi dengan router mikrotik dengan batas user sebanyak maksimal 50 user, apabila terlebih dari 50 user maka resource dari mikrotik akan penuh dan router melambat . ketika user akan melakukan request maka mikrotik akan mengecek apakah user tersebut terdaftar pada server radius maka, apabila username dan password sudah terdaftar pada server, maka user akan mendapatkan response dengan bisa terkoneksi dengan jaringan. Apabila User Di Tolak maka Username dan Password tidak terdaftar pada server sehingga user tidak dapat terkoneksi dengan jaringan. Untuk dapat terkoneksi dengan jaringan, maka user harus mendaftarkan pada 
administrator, kemudian administrator akan melakukan input user pada server radius, sehingga user akan dapat terkoneksi dengan jaringan.

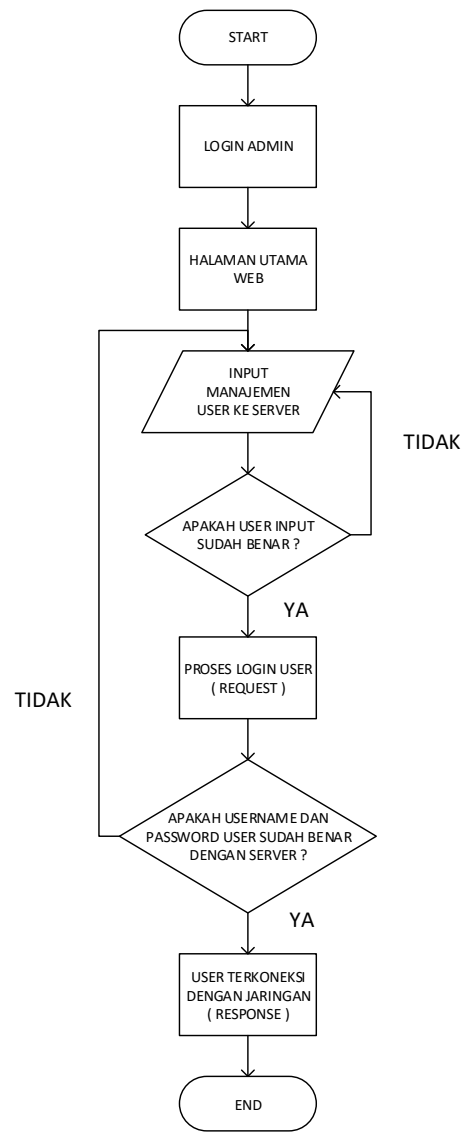

Gambar 3. Flowchart Alur Sistem

\subsection{Diagram Blok}

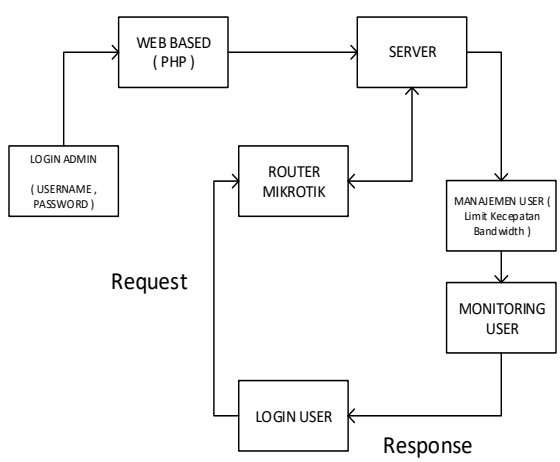

Gambar 4. Diagram Blok Sistem

Pada Gambar 4. merupakan diagram blok dari alur jalan nya sistem, yang berawal dari login admin untuk membuka sistem web based, kemudian admin dapat mengolah data user dari web based yang di buat , dimana data user tersimpan pada server radius yang sudah terkoneksi dengan router mikrotik . ketika user akan melakukan request maka mikrotik akan mengecek apakah user tersebut terdaftar pada server radius maka, user akan mendapatkan response dengan bisa terkoneksi dengan jaringan .dimana user tersebut sebelumnya sudah di manajemen oleh admin. Berikut proses login user:

1. User terhubung dengan hotspot mikrotik

2. User login hotspot dengan username dan password dan request ke mikrotik

3. Mikrotik request login user ke server radius , radius menerima request login, kemudian melakukan otentikasi dan kemudian outorisasi.

\subsection{Struktur Menu}

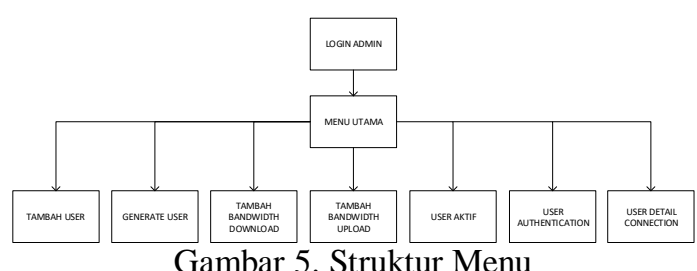

Pada Gambar 5. Menunjukan Bahwa pada struktur website admin terdapat beberapa fitur atau menu yang mendukung administrator untuk mengolah data user, terdapat menu tambah user, generate user, tambah bandwidth download, tambah bandwidth upload, user aktif, user authentication, user detail connection.

\section{HASIL DAN PEMBAHASAN \\ 4.1. Tampilan Login Admin}

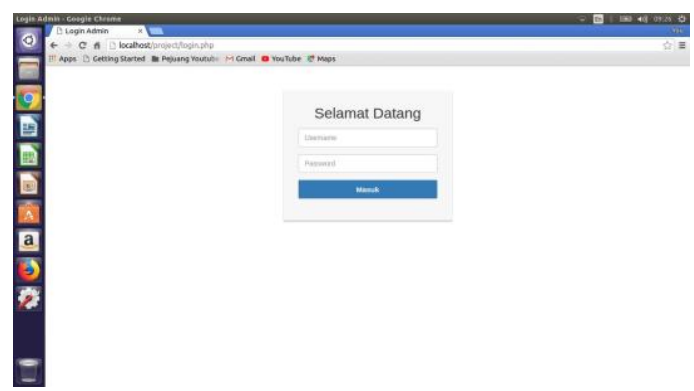

Gambar 6. Tampilan Login Admin

Pada Gambar 6. Merupakan Implementasi dari halaman Login untuk administrator. Dimana Admin Memasukkan username dan password yang sebelumnya telah di buat pada database.

\subsection{Tampilan Halaman Dashboard}

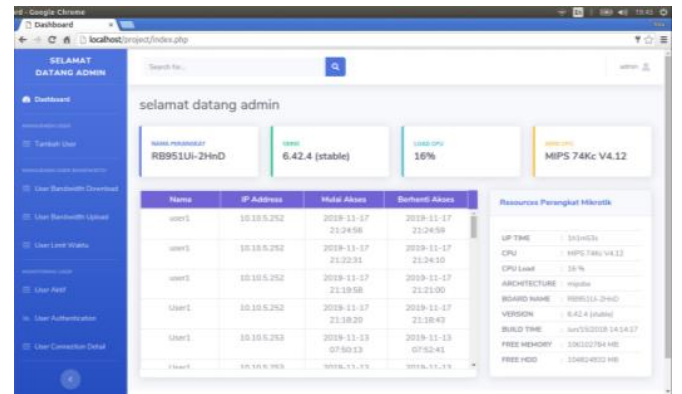

Gambar 7. Tampilan Halaman Dashboard 
Pada Gambar 7. Merupakan implementasi dari halaman dashboard web based admin. Dimana Admin dapat memantau aktifitas Router Mikrotik, seperti resource router mikrotik, CPU Load, Free Memory, Free HDD, Nama Router, Versi Router dan Aktifitas User yang pernah atau sedang terkoneksi dengan jaringan hotspot.

\subsection{Tampilan Halaman Tambah User Hotspot}

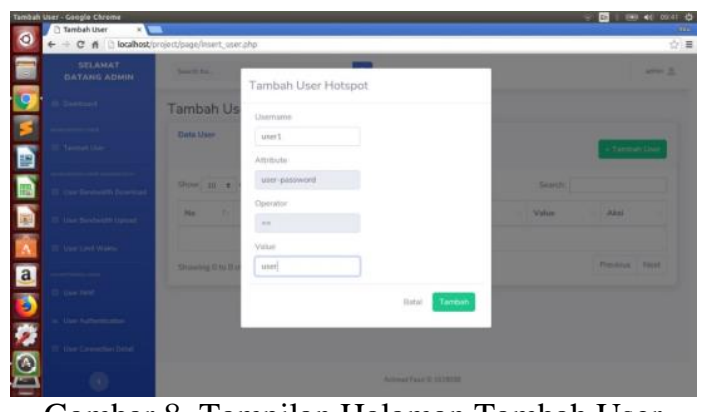

Gambar 8. Tampilan Halaman Tambah User

Pada Gambar 8. Merupakan Halaman Implementasi dari halaman tambah user, terdapat tabel yang menunjukan user yang tersimpan pada database, kemudian terdapat tombol tambah user yang menuju form untuk tambah user .

\subsection{Tampilan Halaman Manajemen Bandwidth}

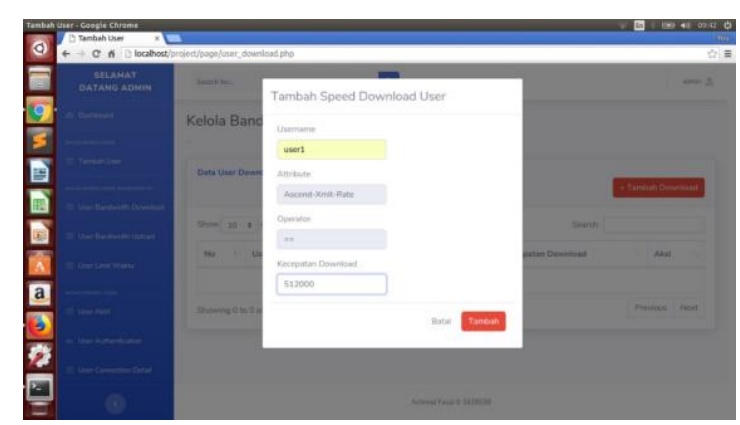

Gambar 9. Tampilan Halaman Manajemen

\section{Bandwidth}

Pada Gambar 9. Pengujian Manajemen Bandwidth User, Pengujian ini berfungsi apakah sistem dapat berjalan baik untuk alokasi bandwidth setiap user, alokasi bandwidth terdiri dari bandwidth download dan upload dan Manajemen untuk batas masa Akfif User.

\subsection{Tampilan Halaman Limit Waktu User}

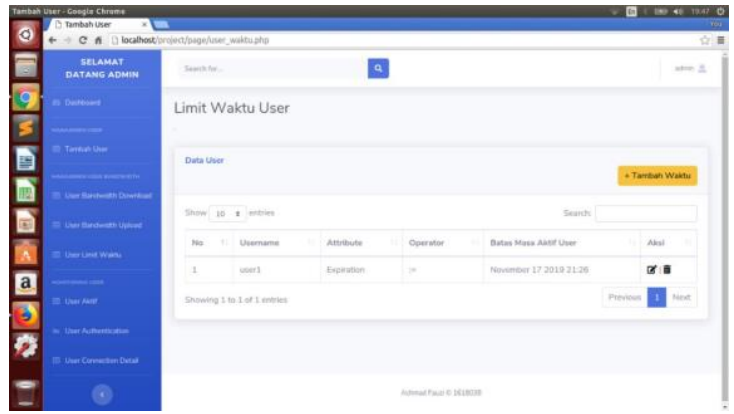

Gambar 10. Tampilan Halaman Limit Waktu User

Pada Gambar 10. Merupakan Pengujian batas masa aktif User mengakses Jaringan Hotspot, ketika masa aktif user akan melewati waktu yang sudah di tentukan administrator, maka user akan otomatis disconnect dan tidak bisa login jaringan tersebut.

\subsection{Pengujian Login User}

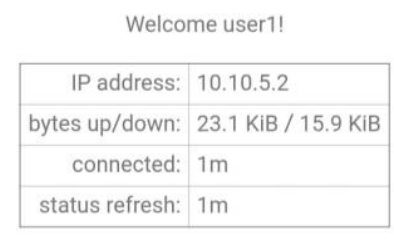

$\log$ off

\section{Gambar 11. Pengujian Login User}

Pada Gambar 11. Merupakan Pengujian Authorization user, setelah melakukan authentication, maka user akan terkoneksi dengan layanan hotspot .

Tabel 1. Pengujian dari sistem authentication dan authorize user.

\begin{tabular}{|c|c|c|c|c|}
\hline \multirow{2}{*}{ No } & \multirow{2}{*}{$\begin{array}{c}\text { User } \\
\text { name }\end{array}$} & $\begin{array}{c}\text { Passwor } \\
\mathbf{d}\end{array}$ & $\begin{array}{c}\text { Authentication } \\
\text { (Login } \\
\text { jaringan) }\end{array}$ & $\begin{array}{c}\text { Authorization } \\
\text { ( Akses } \\
\text { Internet })\end{array}$ \\
\hline 1 & User1 & User11 & Berhasil & Berhasil \\
\hline 2 & User2 & User12 & Berhasil & Berhasil \\
\hline 3 & User3 & User13 & Berhasil & Berhasil \\
\hline 4 & User4 & User14 & Berhasil & Berhasil \\
\hline 5 & User5 & User15 & Berhasil & Berhasil \\
\hline 6 & User6 & User16 & Berhasil & Berhasil \\
\hline 7 & User7 & User17 & Berhasil & Berhasil \\
\hline 8 & User8 & User18 & Berhasil & Berhasil \\
\hline 9 & User9 & User19 & Berhasil & Berhasil \\
\hline 10 & User10 & User100 & Berhasil & Berhasil \\
\hline
\end{tabular}




\subsection{Pengujian Kecepatan Bandwidth User}

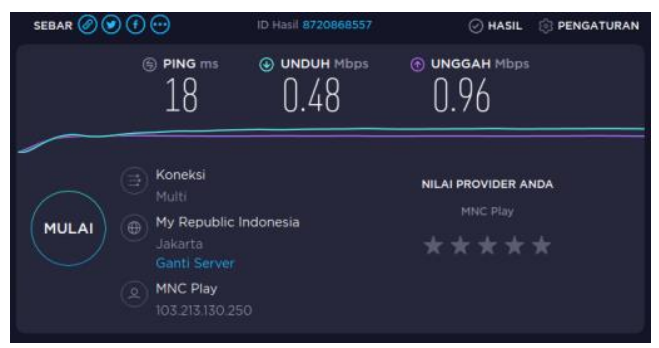

Gambar 12. Hasil Test Bandwidth

Pada Gambar 12. Merupakan pengujian kecepatan bandwidth setiap user, pengujian userl untuk alokasi bandwidth Download sebesar $512 \mathrm{~kb}$ dan Alokasi Bandwidth Upload Sebesar 1Mb.

Tabel 2. Merupakan tabel pengujian manajemen dan kecepatan bandwidth setiap user hotspot .

\begin{tabular}{|c|c|c|c|c|c|}
\hline \multirow{2}{*}{ No } & \multirow{2}{*}{ Username } & \multirow{2}{*}{$\begin{array}{c}\text { IP } \\
\text { Address }\end{array}$} & \multicolumn{2}{|c|}{$\begin{array}{c}\text { Besar Limit } \\
\text { Bandwidth }\end{array}$} & \multirow{2}{*}{ Hasil } \\
\cline { 4 - 5 } & & & Download & Upload & \\
\hline 1 & User1 & 10.10 .5 .2 & $512 \mathrm{~Kb}$ & $1 \mathrm{Mb}$ & Berhasil \\
\hline 2 & User2 & 10.10 .5 .3 & $1 \mathrm{Mb}$ & $512 \mathrm{~Kb}$ & Berhasil \\
\hline 3 & User3 & 10.10 .5 .4 & $1 \mathrm{Mb}$ & $512 \mathrm{~Kb}$ & Berhasil \\
\hline 4 & User4 & 10.10 .5 .5 & $512 \mathrm{~Kb}$ & $1 \mathrm{Mb}$ & Berhasil \\
\hline 5 & User5 & 10.10 .5 .6 & $512 \mathrm{~Kb}$ & $1 \mathrm{Mb}$ & Berhasil \\
\hline 6 & User6 & 10.10 .5 .7 & $512 \mathrm{~Kb}$ & $1 \mathrm{Mb}$ & Berhasil \\
\hline 7 & User7 & 10.10 .5 .8 & $1 \mathrm{Mb}$ & $1 \mathrm{Mb}$ & Berhasil \\
\hline 8 & User8 & 10.10 .5 .9 & $1 \mathrm{Mb}$ & $512 \mathrm{~Kb}$ & Berhasil \\
\hline 9 & User9 & 10.10 .5 .10 & $1 \mathrm{Mb}$ & $1 \mathrm{Mb}$ & Berhasil \\
\hline 10 & User10 & 10.10 .5 .11 & $256 \mathrm{~Kb}$ & $512 \mathrm{~Kb}$ & Berhasil \\
\hline
\end{tabular}

Tabel 3. Pengujian Limit Waktu User

\begin{tabular}{|c|c|c|c|c|c|c|}
\hline \multirow{2}{*}{ No } & \multirow{2}{*}{$\begin{array}{c}\text { User } \\
\text { name }\end{array}$} & $\begin{array}{c}\text { Tang } \\
\text { gal }\end{array}$ & Bulan & $\begin{array}{c}\text { Tahu } \\
\text { n }\end{array}$ & Jam & \multirow{2}{*}{ Hasil } \\
\hline 1 & User1 & 21 & November & 2019 & $19: 50$ & Berhasil \\
\hline 2 & User2 & 17 & November & 2019 & $21: 25$ & Berhasil \\
\hline 3 & User3 & 13 & November & 2019 & $07: 52$ & Berhasil \\
\hline 4 & User4 & 02 & Desember & 2019 & $13: 30$ & Berhasil \\
\hline 5 & User5 & 06 & Desember & 2019 & $20: 25$ & Berhasil \\
\hline 6 & User6 & 09 & Desember & 2019 & 17.15 & Berhasil \\
\hline 7 & User7 & 06 & Januari & 2020 & $20: 20$ & Berhasil \\
\hline 8 & User8 & 06 & Januari & 2020 & $09: 50$ & Berhasil \\
\hline 9 & User9 & 06 & Januari & 2020 & $10: 00$ & Berhasil \\
\hline 10 & User10 & 06 & Januari & 2020 & $10: 00$ & Berhasil \\
\hline
\end{tabular}

Pengujian Limit Waktu User untuk menentukan berakhirnya masa aktif user yang terkoneksi dengan jaringan, apabila masa aktif sudah melewati waktu yang sudah ditentukan maka user tidak dapat terkoneksi dengan jaringan atau juga disebut dengan sistem Billing.

\subsection{Pengujian Monitoring User Aktif}

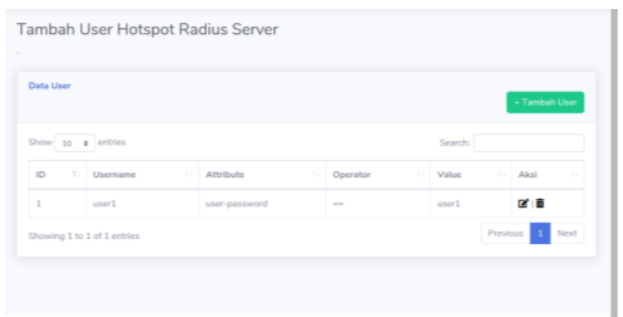

Gambar 13. Tampilan Monitoring User Aktif
Pada Gambar 13. Merupakan Halaman Implementasi dari halaman User Authentication yang dimana halaman ini admin dapat memantau aktifitas user yang akses di terima oleh server, terdapat tanggal dan waktu user tersebut mulai mengakses jaringan .

\subsection{Pengujian Log User Authentication}

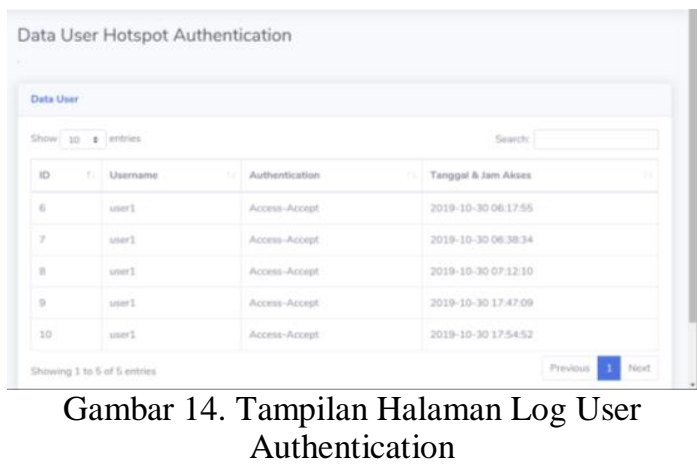

Pada Gambar 14. Merupakan Halaman Implementasi dari halaman User Authentication yang dimana halaman ini admin dapat memantau aktifitas user yang akses di terima oleh server, terdapat tanggal dan waktu user tersebut mulai mengakses jaringan .

\subsection{Pengujian Log User Connection Detail}

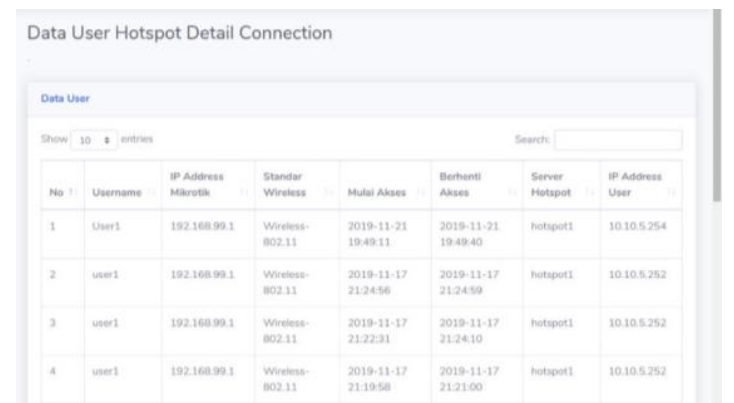

Gambar 15. Tampilan Halaman Log User Connection Detail

Pada Gambar 15. Merupakan Pengujian Monitoring Log Dari User, Fungsi ini admin dapat memantau user yang pernah ter-akses dengan jaringan,terdapat mulai waktu akses user, akhir waktu akses user, ip address user, standart wifi yang digunakan .

\subsection{Pengujian Server Radius Pada Linux Ubuntu}

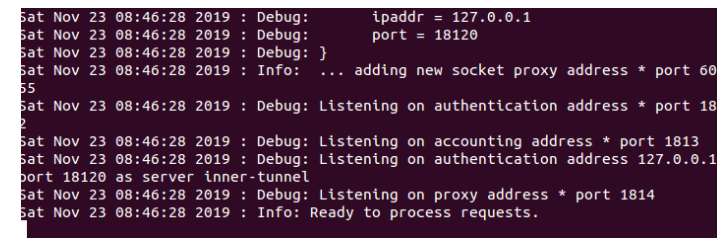

Gambar 16. Pengujian Server Radius 
Pada Gambar 16. Pengujian Server radius, untuk melihat apakah terjadi error atau tidak, dengan perintah sudo freeradius $-X X X$, apabila terdapat error maka akan terlihat report pada konfigurasi file yang terjadi kesalahan konfigurasi, apabila pengujian berhasil maka akan muncul report Ready To Process Request.

\subsection{Pengujian Notifikasi Email}

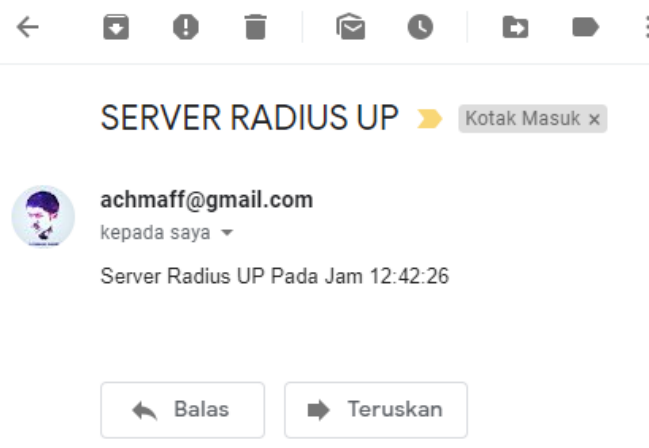

Gambar 17. Pengujian Notifikasi Email

Pada Gambar 17. Merupakan Notifikasi, yang di kirimkan oleh router melalui Email, fungsi notifikasi ini untuk memantau Aktifitas Server, Ketika Router Sedang $U p$ maupun sedang Down.

Pada Tabel 4. Merupakan Tabel Pengujian Monitoring Keseluruhan dari fungsional sistem .

Tabel 4. Tabel Pengujian Monitoring Sistem

\begin{tabular}{|c|c|c|c|c|c|}
\hline \multirow[b]{2}{*}{$\begin{array}{l}\mathbf{N} \\
\mathbf{o}\end{array}$} & \multirow[b]{2}{*}{$\begin{array}{l}\text { User } \\
\text { name }\end{array}$} & \multicolumn{3}{|c|}{ Monitoring } & \multirow[b]{2}{*}{ Hasil } \\
\hline & & $\begin{array}{c}\text { IP } \\
\text { Address }\end{array}$ & $\begin{array}{c}\text { MAC } \\
\text { Address }\end{array}$ & $\begin{array}{c}\text { Waktu } \\
\text { Akses User }\end{array}$ & \\
\hline 1 & User1 & 10.10 .5 .2 & $\begin{array}{l}\text { 20:5E:F7: } \\
\text { EC:E9:94 }\end{array}$ & $\begin{array}{c}2019-11-21 \\
19: 49: 11\end{array}$ & Berhasil \\
\hline 2 & User2 & 10.10 .5 .3 & $\begin{array}{c}\text { 74:DF:BF: } \\
60: F A: 53\end{array}$ & $\begin{array}{c}2019-11-17 \\
21: 24: 56\end{array}$ & Berhasil \\
\hline 3 & User3 & 10.10 .5 .4 & $\begin{array}{c}70: 8 \mathrm{~B}: \mathrm{CD}: \\
71: \mathrm{E} 9: 70\end{array}$ & $\begin{array}{c}2019-11-13 \\
07: 50: 13\end{array}$ & Berhasil \\
\hline 4 & User4 & 10.10 .5 .5 & $\begin{array}{l}\text { CC:2D:83: } \\
\text { A4:0D:7F }\end{array}$ & $\begin{array}{c}2019-12-02 \\
13: 29: 16\end{array}$ & Berhasil \\
\hline 5 & User5 & 10.10 .5 .6 & $\begin{array}{l}\text { 08:7F:98: } \\
\text { D1:4D:A5 }\end{array}$ & $\begin{array}{c}2019-12-06 \\
20: 24: 31\end{array}$ & Berhasil \\
\hline 6 & User6 & 10.10 .5 .7 & $\begin{array}{l}\text { CC:2D:83: } \\
\text { BA:2A:62 }\end{array}$ & $\begin{array}{c}2019-12-09 \\
17: 12: 25\end{array}$ & Berhasil \\
\hline 7 & User7 & 10.10 .5 .8 & $\begin{array}{l}\text { 20:5E:F7: } \\
\text { EC:E9:94 }\end{array}$ & $\begin{array}{c}2020-01-06 \\
20: 15: 45\end{array}$ & Berhasil \\
\hline 8 & User8 & 10.10 .5 .9 & $\begin{array}{l}\text { 20:5E:F7: } \\
\text { EC:E9:94 }\end{array}$ & $\begin{array}{c}2020-01-06 \\
09: 48: 19\end{array}$ & Berhasil \\
\hline 9 & User9 & 10.10 .5 .10 & $\begin{array}{l}\text { 20:5E:F7: } \\
\text { EC:E9:94 }\end{array}$ & $\begin{array}{c}2020-01-06 \\
09: 54: 35\end{array}$ & Berhasil \\
\hline 10 & User10 & 10.10 .5 .11 & $\begin{array}{c}\text { 0C:98:38:1 } \\
9: 49: 97\end{array}$ & $\begin{array}{c}2020-01-06 \\
09: 54: 35\end{array}$ & Berhasil \\
\hline
\end{tabular}

Pada Tabel 5. Merupakan Tabel Pengujian AAA yang telah di bangun oleh penulis
Tabel 5. Tabel Pengujian AAA

\begin{tabular}{|c|c|c|c|c|}
\hline \multirow[b]{2}{*}{$\begin{array}{l}\mathbf{N} \\
\mathbf{o}\end{array}$} & \multirow[b]{2}{*}{$\begin{array}{c}\text { Userna } \\
\text { me }\end{array}$} & \multicolumn{3}{|c|}{ Hasil } \\
\hline & & $\begin{array}{c}\text { Login } \\
\text { (Authenticati } \\
\text { on) }\end{array}$ & $\begin{array}{c}\text { Akses } \\
\text { Jaringan } \\
\text { (Authorize) }\end{array}$ & $\begin{array}{c}\text { Manaje } \\
\text { men } \\
\text { User } \\
\text { (Accoun } \\
\text { ting) }\end{array}$ \\
\hline 1 & User1 & Berhasil & Berhasil & Berhasil \\
\hline 2 & User2 & Berhasil & Berhasil & Berhasil \\
\hline 3 & User3 & Berhasil & Berhasil & Berhasil \\
\hline 4 & User4 & Berhasil & Berhasil & Berhasil \\
\hline 5 & User5 & Berhasil & Berhasil & Berhasil \\
\hline 6 & User6 & Berhasil & Berhasil & Berhasil \\
\hline 7 & User7 & Berhasil & Berhasil & Berhasil \\
\hline 8 & User8 & Berhasil & Berhasil & Berhasil \\
\hline 9 & User9 & Berhasil & Berhasil & Berhasil \\
\hline 10 & User10 & Berhasil & Berhasil & Berhasil \\
\hline
\end{tabular}

\section{KESIMPULAN DAN SARAN}

\subsection{Kesimpulan}

Berdasarkan Hasil dari Rancang Bangun Sistem Manajemen User dan Monitoring yang telah dilakukan maka didapat beberapa kesimpulan sebagai berikut:

1. Pengujian Server Radius dengan sistem operasi Linux Ubuntu dapat berjalan $100 \%$.

2. Fungsionalitas Manajemen user pada sistem dapat berjalan $100 \%$, dengan pengujian 10 user dan dapat dimanajemen pada bandwidth dan masa aktif user .

3. Fungsionalitas Monitoring user pada sistem dapat berjalan $100 \%$, dengan pengujian 10 user sistem dapat mencatat aktivitas login user ketika terkoneksi dengan jaringan hotspot .

4. Dari pengujian sistem, sistem dapat di jalankan pada sistem operasi Linux, Windows, dan Android(mobile) .

5. Dari pengujian sistem dapat berjalan dengan baik menggunakan bahasa pemrograman $P H P$ dan MySQL sebagai database.

\subsection{Saran}

Adapun saran setelah melakukan pengujian, agar kedepannya sistem ini dapat dikembangkan yaitu sebagai berikut :

1. Sistem memiliki fitur untuk memutuskan koneksi user hotspot.

2. Sistem dapat memiliki Report dalam bentuk dokumen, agar pelaporan terhadap aktifitas jaringan lebih mudah.

3. Melakukan pengelompokan terhadap user pada fitur limitasi waktu, agar dapat memudahkan administrator ketika user yang di kelola memiliki kapasitas yang sangat banyak 


\section{DAFTAR PUSTAKA}

[1] Yuliansyah, H. (2015, July). Optimalisasi RADIUS Server sebagai Sistem Otentikasi dan Otorisasi untuk Proses Login Multi Aplikasi Web Berbasis PHP. In Seminar Nasional Informatika (SEMNASIF) (Vol. 1, No. 3).

[2] Febyatmoko, G. S., Hidayat, T., \& Setiawan, M. A. (2006). Sistem Otentikasi, Otorisasi, Dan Pelaporan Koneksi User Pada Jaringan Wireless Menggunakan Chillispot Dan Server Radius. Jurnal Fakultas Hukum UII, 4(1).

[3] Lizarti, N., \& Agustin, W. (2015). Aplikasi Network Traffic Monitoring Menggunakan Simple Network Management Protocol (SNMP) pada Jaringan Virtual Private Network (VPN). SATIN-Sains dan Teknologi Informasi, 1(1), 27-3
[4] Hermawan, D. K., Sudarsono, A., \& Winarno, I. (2012). Implementasi Bandwith Management Captive Portal Pada Jaringan Wireless Di Pens ITS. Politeknik Electronika Negeri Surabaya.

[5] Wulandari, R. (2016). Analisis QoS (Quality of Service) Pada Jaringan Internet (Studi Kasus: UPT Loka Uji Teknik Penambangan Jampang Kulon-LIPI). Jurnal Teknik Informatika dan Sistem Informasi, 2(2).

[6] Sridianti, 2015,' perbedaan wifi dan hotspot',https://www.sridianti.com/perbedaan-wifidan-hotspot.html,2019

[7] Irawan, D.J., Adriantantri, E. and Prasetio, S., 2012. Sistem Informasi Akademik Berbasis SMS. Jurnal Teknik Informatika, 47. 